\title{
The grand challenges in Gl tract cancers
}

\author{
Mauro Risio* \\ Department of Pathology, Institute for Cancer Research and Treatment, Candiolo, Torino, Italy \\ *Correspondence: mauro.risio@ircc.it
}

\section{STOCHASTIC MODELING OF TUMOR PROGRESSION: GI TRACT CANCERS AS A PARADIGM}

Historically, the founding paradigm has been that cancers of the gastrointestinal tract are preceded by a pre-invasive stage of intraepithelial neoplasia. From the morphological standpoint the term "dysplasia" has been conventionally applied to the collection of changes in cellular morphology and tissue architecture that define intraepithelial neoplasia. Although morphologically different according to the specific GI tract anatomic location (Barrett-associated, gastritis- and non-gastritis-associated, adenomatous and serrated dysplasia; Odze et al., 2010) the severity of intraepithelial neoplasia is estimated from the degree of deviation from the normal tissue of origin, and the neoplastic process has been thought to progress univocally toward carcinoma through dysplasia of increasing severity. There now exists evidence to construe the natural history of tumor progression in GI tract in accordance with a stochastic model, in which each stage is probabilistically linked with different evolutive pathways (progression, stabilization, regression) rather than deterministically associated with the onset of carcinoma (Risio, 2010). Moreover, even if biological reasons support dysplasia as the most predictive marker of the cancerization risk, the links between non-morphological features of precursors and their malignant transformation is greater than the one linking dysplasia and malignancy, at least in the colonic carcinogenesis. New biomarkers are therefore needed, to define the magnitude of risk and the times of progression for each step of tumorigenesis, in order to rationally schedule surveillance and follow-up of patients with diagnosed GI tract neoplasia and to plan suitable population-based cancer prevention interventions.

\section{EQUIVOCAL CANCER PRECURSORS: OLD} MIMICKERS OR NEW ENTITIES?

"Origin of Colorectal Cancers in Hyperplastic Polyps and Serrated Adenomas: Another Truism Bites the Dust" was the title-page of the Editorial by Hamilton (2001). Ten years later we are fully aware of those serrated polyps, mainly with sessile configuration that, though obscured by a low histopathologic diagnostic reproducibility (Vieth et al., 2011), subtly mimic the innocent, non-cancerous, hyperplastic polyps. Knowledge has also been gained about the molecular machinery driving and sustaining the growth of sessile serrated lesions: they are unlikely to progress (at any rate with a low evolutive speed) toward cancer. Worries persist however, considering that a subset of these lesions appears to give rise to carcinoma when less than a few millimeters in size and, most importantly, that the vast majority of interval colon cancers are more likely than non-interval colon cancers to arise from serrated lesions (Sawhney et al., 2006).

Two critical issues, which need to be specifically addressed, are the following:

(i) To profile the morphological and/ or genetic phenotype of the serrated lesions actually engaged in the "serrated polyp neoplasia pathway";

(ii) To standardize the effective use of the new endoscopic techniques (e.g.,: magnifying chromoendoscopy) in order to improve the detection rates of those not easily identifiable GI cancer precursors, such as sessile serrated and non-polypoid adenomatous lesions.

\section{AT THE INTERSECTION BETWEEN HEREDITARY AND SPORADIC NEOPLASIA: FAMILIAL CANCERS}

Familial cancers account for nearly 25\% of all GI tract cancers and are a heterogeneous group encompassing patients with seemingly sporadic tumors that aggregate in families, in the absence of true and recognized hereditary syndromes (Castells et al., 2009). While the well-established hereditary syndromes feature a Mendelian inheritance pattern, familial cancers are likely to be a consequence of the co-inheritance of multiple, low-penetrance variants, susceptibility genes that confer predisposition to cancers. Non-syndromic familial cancers require, according to the familial risk stratification, specific diagnostic, therapeutic, and preventive strategies, not completely defined yet. Cancer risk, however, is the result of complex interactions between genetic and non-genetic (lifestyle/dietary) risk factors. Epidemiological studies have identified several dietary risk factors for both gastric and colorectal neoplasia and common genetic variants are likely to interact with them to modify the overall risk. On the other hand, assessing the interplay between inherited and non-genetic factors could turn out predictive of the effectiveness of chemoprevention interventions and micronutrient supplementations (Tomlinson et al., 2010). In this setting, non-syndromic familial GI tract cancers are likely to become a privileged scenario for personalized, predictive medicine (Castells et al., 2009).

\section{EARLY CANCER: REFINING THE CURATIVE ENDOSCOPIC TREATMENT}

To ensure the curative potential of endoscopic resection of gastrointestinal early cancers, treatment should be limited to lesions with no or minimal risk of metastatic diffusion. Combining polypectomy, mucosal resection and, more recently, submucosal dissection more than half of GI cancers in early stages can be endoscopically removed (Kakushima and Fujishiro, 2008). En bloc resection of neoplasms is crucial in that it allows the precise histopathologic evaluation of the specimen in order to stratify the treatment outcomes and the patient's prognosis. Here however, we are acting according to empiric rather than heuristic criteria. Evidence is lacking, at the current time concerning the minimal distance cancer border-resection margins defining the R0 endoscopic removal, on which the recurrence rates of the lesions depend. Similarly, the minimal depth of colonic submucosa cancer invasion associated with metastatic potential 
that is of paramount importance in predicting long-term outcomes has to be defined yet.

\section{TARGETING GENES, PATHWAYS, AND NETWORKS: KNOTS IN BIOLOGICAL THERAPIES}

Constitutive activation of the EGFR/RAS/ PI3K cell-signaling pathway due to gene somatic mutations in core pathway components occurs in GI tract cancers and needs predictive biomarkers of response to the biological therapies specifically targeting this pathway. In this way, EGFR-targeted monoclonal antibody therapies (such as cetuximab and panitumumab) are undergoing extensive clinical evaluation in recurrent or first line metastatic colorectal cancer, mutational status of KRAS and BRAF genes providing the predictive markers for anti-EGFR therapy resistance. Similarly, the monoclonal antibody against VEGFR, bevacizumab, in combination with 5-FU/leucovorin and/or irinotecan has been shown to improve survival of patients with advanced colorectal cancer, although reliable predictive markers are not available yet. Such a single gene-based approach has driven the research during the last years, in spite of its well known methodological and conceptual restrictions. Cancer heterogeneity represents a major concern in testing predictive biomarkers, in that the clonal expansion and the intratumor spatial distribution of emerging subclones are not currently predictable, impairing the sensitivity of tissue-based essays. Most importantly, cancer genome operates as a whole biological system due to the functional role of cancer genes exerted through their mutual, RNA, microRNAs, and protein-DNA interactions, comprehensively included under the categories of transcriptomes and interactomes. (Network modeling, to be pursued by the forthcoming translational research is needed to optimize the effectiveness of biological targeting of cancer cells in an individual tumor. The aim is to move from the traditional "trial and error" toward a personalized approach also in the adjuvant setting (Deschoolmeester et al., 2010).

\section{ASSOCIATIONS AND EFFECTS: WHAT AND HOW TO MEASURE IN MULTIMODAL TREATMENTS}

Despite intensive and focused research no biomarkers have been found which are predictive of responsiveness to chemoradiation of rectal cancer and transferable to clinical practice. Among the limiting factors, the lack of reliable clinical diagnostic tools to accurately predict the pathological tumor response plays a role. In effect, preoperative radiology has been shown to overestimate down staging of the tumor and pathologic evaluation of the resected specimens remains the best and most accurate method for assessing pathologic response to preoperative chemoradiation in rectal (Glynne-Jones et al., 2008), esophageal (Wu et al., 2007) primaries, and in colorectal liver metastases (Rubbia-Brandt et al., 2007). None of the histopathological classifications of carcinoma response to neo-adjuvant therapies, however, consider the viability of the residual, morphologically identifiable neoplastic cells, which is the real predictor of tumor re-growth and progression. Consequently, investigations should be aimed at:

- Defining finely tuned histopathologic features (apoptosis, necroptosis, cancer stem cell niches) to be related to the specific integrated therapies and establishing histological tumor regression grading systems specific for these therapeutic modalities.

- Designing appropriate clinical validation studies in regard to long-term outcomes and clinical vs pathological complete response concordance.

\section{CONTROLLING CANCER: THE EMERGING ROLE OF SCREENING PROGRAMS}

Although the substantial improvement in survival derived from the new treatments and primary prevention bears potential on the long run, screening so far seems to offer the best possibility for reducing colorectal cancer mortality. While few screening tests have been proven effective in reducing colorectal cancer incidence (sigmoidoscopy) and mortality (FOBT and sigmoidoscopy; Segnan et al., 2011), others (stool DNA, Computed Tomographic Colonography) need to be further investigated and evaluated in terms of effectiveness and cost/ effectiveness. Microstimulation models have been built up depicting the transition probabilities, duration in states and time of events throughout the growth, and the malignant transformation of adenomas useful to define the appropriate ages and intervals for cancer screening (Zauber et al.,
2008). The availability of innovative screening tests, together with the combinations of different screening intervals and selectively targeted risk groups, results in an exciting scenario, promoting, and intensifying the research to optimize colorectal cancer screening programs.

We believe these frontiers worthy of being focused, investigated, discussed, and criticized. Frontiers in GI cancers is aimed at supporting multidisciplinary research to speed up clinical applications of biological advances. Manuscripts are welcomed, therefore, dealing with tumorigenesis, prevention, early detection, and treatment of GI tract neoplasia.

\section{REFERENCES}

Castells, A., Castellvi-Bel, S., and Balaguer, F. (2009). Concepts in familial colorectal cancer: where do we stand and what is the future? Gastroenterology 137, 404-409.

Deschoolmeester, V., Baay, M., Specenier, P., Lardon, F., and Vermorken, J. B. (2010). A review of the most promising biomarkers in colorectal cancer: one step closer to targeted therapy. Oncologist 15, 699-731.

Glynne-Jones, R., Wallace, M., Livingstone, J. I., and Meyrick-Thomas, J. (2008). Complete clinical response after preoperative chemoradiation in rectal cancer: is a "wait and see" policy justified? Dis. Colon Rectum 51, 10-19.

Hamilton, S. R. (2001). Origin of colorectal cancers in hyperplastic polyps and serrated adenomas: another truism bites the dust. J. Natl. Cancer Inst. 93 , 1282-1283.

Kakushima, N., and Fujishiro, M. (2008). Endoscopic submucosal dissection for gastrointestinal neoplasms. World J. Gastroenterol. 14, 2962-2967.

Odze, R. D., Riddell, R. H., Bosman, F. T., Carneiro, F., Flejou, J.-F., Genta, R. M., Geboes, K., Hattori, T., Lawers, G. Y., Offerhaus, G. J. A., Rugge, M., Shimizu, M., Shimoda, T., Vieth, M, and van Krieken, J. H. J. M. (2010). "Premalignant lesions of the digestive tract," in WHO Classification of Tumours of the Digestive System, 4th Edn, eds F. T. Bosman, F. Carneiro, R. H. Hruban, and N. D. Theise (Lyon: IARC), 10-12.

Risio, M. (2010). The natural history of adenomas. Best Pract. Res. Clin. Gastroenterol. 24, 397-406.

Rubbia-Brandt, L., Giostra, E., Brezault, C., Roth, A. D., Andres, A., Audard, V., Sartoretti, P., Dousset, B., Majno, P. E., Soubrane, O., Chaussade, S., Mentha G., and Terris, B. (2007). Importance of histological tumor response assessment in predicting the outcome in patients with colorectal liver metastases treated with neo-adjuvant chemotherapy followed by liver surgery. Ann. Oncol. 18, 299-304.

Sawhney, M. S., Farrar, W. D., Gudiseva, S., Nelson, D. B., Lederle, F. A., Rector, T. S., and Bond, J. H. (2006). Microsatellie instability in interval colon cancers. Gastroenterology 131, 1700-1705.

Segnan, N., Armaroli, P., Bonelli, M., Risio, M., Sciallero, S., Zappa, M., Andreoni, B., Arrigoni, A., Bisanti, L., Casella, C., Crosta, C., Falcini, F., Ferrero, F., Giacomin, A., Giuliani, O., Santarelli, A., Visioli, C. B., Zanetti, R., Atkin, W. S., Senore, C., and SCORE Working Group. 
(2011). Once only sigmoidoscopy in colorectal cancer screening: follow-up findings of the italian randomized controller trial-SCORE. J. Natl. Cancer Inst. $103,1310-1322$.

Tomlinson, I. P., Dunlop, M., Campbell, H., Zanke, B., Gallinger, S., Hudson, T., Koessler, T., Pharoah, P. D., Niittymäki, I., Tuupanen, S., Aaltonen, L. A., Hemminki, K., Lindblom, A., Försti, A., Sieber, O., Lipton, L., van Wezel, T., Morreau, H., Wijnen, J. T., Devilee, P., Matsuda, K., Nakamura, Y., Castellví-Bel, S., Ruiz-Ponte, C., Castells, A., Carracedo, A., Ho, J. W., Sham, P., Hofstra, R. M., Vodicka, P., Brenner, H., Hampe, J., Schafmayer, C., Tepel, J., Schreiber, S., Völzke, H., Lerch, M. M., Schmidt, C. A., Buch, S., Moreno, V., Villanueva, C. M., Peterlongo, P., Radice, P., Echeverry, M. M., Velez, A., Carvajal-Carmona, L., Scott, R., Penegar, S., Broderick, P., Tenesa, A., and Houlston, R.S. (2010). COGENT (COlorectal cancer
GENeTics): an international consortium to study the role of polymorphic variation on the risk of colorectal cancer. Br. J. Cancer 102, 447-454.

Vieth, M., Quirke, P., Lambert, R., von Karsa, L., and Risio, M. (2011).Annex to Quirke et al. quality assurance in pathology in colorectal cancer screening and diagnosis: annotations of colorectal lesions. Virchows Arch. 458, 21-30.

Wu, T. T., Chirieac, L. R., Abraham, S. C., Krasinskas, A. M., Wang, H., Rashid, A., Correa, A. M., Hofstetter, W. L., Ajani, J. A., and Swisher, S. G. (2007). Excellent interobserver agreement on grading the extent of residual carcinoma after preoperative chemoradiation in esophageal and esophagogastric junction carcinoma: a reliable predictor for patient outcome. Am. J. Surg. Pathol. 31, 58-64.

Zauber, A. G., Lansdorp-Vogelaar, I., Knudsen, A. B., Wilschut, J., van Ballegooijen, M., and Kuntz, K.
M. (2008). Evaluating test strategies for colorectal cancer screening: a decision analysis for the U.S. preventive services task force. Ann. Intern. Med. 149, 659-669.

Received: 26 October 2011; accepted: 08 November 2011; published online: 23 November 2011.

Citation: Risio M (2011) The grand challenges in GI tract cancers. Front. Oncol. 1:46. doi: 10.3389/ fonc. 2011.00046

This article was submitted to Frontiers in Gastrointestinal Cancers, a specialty of Frontiers in Oncology.

Copyright (c) 2011 Risio. This is an open-access article subject to a non-exclusive license between the authors and Frontiers Media SA, which permits use, distribution and reproduction in other forums, provided the original authors and source are credited and other Frontiers conditions are complied with. 